\title{
PENDIDIKAN KARAKTER BANGSA \\ BERBASIS STRATEGI PEMBELAJARAN PAKEM \\ MELALUI PERMAINAN CINCIN DI JEMPOL TANGAN \\ (Karya Inovasi Pembelajaran Sekolah Dasar)
}

\author{
Ani Adibatin \\ ani_adibatin@gmail.com \\ Unit Pelaksana Teknis Daerah Pendidikan dan Kebudayaan \\ Kecamatan Tuntang - Semarang
}

\begin{abstract}
ABSTRAK
Berhasil tidaknya pencapaian tujuan pembelajaran sangat ditentukan oleh kemampuan guru dalam mengelola kelas, mengelola siswa, memilih strategi pembelajaran, serta kebermaknaan dalam memberikan tugas pada siswa. Berkaitan dengan permasalahan tersebut, penulis sebagai pengawas mengembangkan alat permainan inovatif yang bisa dipakai oleh semua guru, baik guru kelas, guru mata pelajaran, maupun guru ekstra kurikuler. Alat permainan ini bisa dipakai oleh semua siswa dari berbagai tingkatan kelas, berbagai tingkat jenjang sekolah, dan untuk pembelajaran materi yang berbeda. Alat permainan inovatif pembelajaran ini dikembangkan dengan tujuan agar peserta didik bisa belajar sambil bermain dan bermain sambil belajar. Disamping itu, untuk membantu para guru dalam menanamkan pendidikan karakter, sehingga peserta didik menjadi anak yang berkarakter, berwatak sesuai dengan nilai-nilai Pancasila demi terwujudnya tujuan pendidikan nasional. Uji coba alat permainan inovatif ini dilakukan di 9 SD binaan Kecamatan Tuntang. Dari hasil uji coba diperoleh temuan bahwa ada perbedaan yang sangat signifikan antara pendidikan karakter pada pembelajaran tanpa alat permainan inovatif dibandingkan dengan pembelajaran yang menggunakan alat permainan cincin akik di jempol tangan. Nilai rata-rata pembelajaran tanpa alat inovatif $76,55 \%$, sedangkan nilai rata-rata dengan menggunakan alat permainan cincin akik di jempol sebesar 86,88 \% . Hasil pembelajaran menggunakan alat peraga inovatif ini menunjukkan bahwa melalui strategi pembelajaran PAKEM dengan bermain cincin akik di jempol tangan dapat membangun karakter peserta didik sampai 11,33\%.
\end{abstract}

Kata kunci : Nilai-nilai pendidikan karakter bangsa, perrmainan cincin, pembelajaran PAKEM.

\section{PENDAHULUAN}

Menurut Undang-Undang No. 20 Tahun 2003 Bab II Pasal 3, Pendidikan nasional berfungsi mengembangkan kemampuan dan membentuk watak serta peradaban bangsa yang bermartabat dalam rangka mencerdaskan kehidupan bangsa, bertujuan untuk mengembangkan potensi peserta didik agar menjadi manusia yang 
beriman dan bertakwa kepada Tuhan Yang Maha Esa, berakhlak mulia, sehat, berilmu, cakap, kreatif, mandiri, dan menjadi warga negara yang demokratis serta bertanggung jawab. Ada dua hal penting yang harus diwujudkan oleh lembaga pendidikan. Yaitu mengembangan kemampuan yang berkaitan dengan otak yang merujuk pada kualitas akademik, dan membentuk watak yang berkaitan dengan hati yang merujuk pada lulusan yang berakhlak mulia.

Sudah tidak bisa kita pungkiri bahwa globalisasi memberikan dampak yang luar biasa. Perkelahian, pembegalan, tawuran, maupun tindak kekerasan lainnya terjadi dimana-mana. Cara-cara yang dilakukan untuk memperoleh kemakmuran sudah menyimpang kearah negative seperti : sifat licik, serakah, dan egois. Permasalahan ini disebabkan oleh manusia sendiri yang tidak memiliki karakter yang baik.

Bagaimana upaya kita untuk mengatasi tindakan-tindakan negative tersebut? Salah satu upaya yang perlu segera kita lakukan adalah dengan penanaman karakter sejak dini, sehingga dapat menjadi benteng dari masing-masing pribadi agar tercipta pribadi yang berkarakter. Adapun salah satu cara dalam pembentukan karakter adalah dengan memberikan pendidikan karakter di Sekolah, misalnya dengan mengintegrasikan kedalam mata pelajaran, dengan melalui pembiasaan, dengan melalui kegiatan ekstra kurikuler, maupun melalui kegiatan lain yang sesuai.

\section{TINJAUAN PUSTAKA}

\section{Tinjauan Tentang Pendidik Dan Tenaga Kependidikan Profesional}

Pendidik dan tenaga kependidikan mempunyai peran yang sangat penting dalam mewujudkan tujuan pendidikan nasional. Guru adalah pendidik profesional dengan tugas utama mendidik, mengajar, membimbing, mengarahkan, melatih, menilai, serta mengevaluasi peserta didik dalam upaya membentuk insan Indonesia yang cerdas, kompetitif, dan berdaya saing tinggi untuk menghadapi persaingan global. Sejalan dengan hal tersebut guru harus melakukan berbagai kegiatan pengembangan keprofesionalannya (Pedoman lomba inovasi pembelajaran PTK SD Tingkat Nasional: 2015 : 3).

Dalam usaha pengembangan keprofesionalan, guru memerlukan seorang pembimbing,/pembina yaitu seorang pengawas sekolah. Pengawas bukan saja memperbaiki kemampuan mengajar tetapi juga untuk mengembangkan potensi kualitas guru (Sahertian, 2000: 19). Pengawas bertugas sebagai supervisor pendidikan. Dictionary of education board center (dalam Sahertian, 2000: 17) menyatakan bahwa supervisi pendidikan adalah usaha-usaha dari petugas-petugas sekolah dalam memimpin guru-guru dan petugas-petugas lainnya dalam memperbaiki pengajaran. 


\section{Tinjauan Tentang Pendidikan Karakter Bangsa}

Karakter hakikatnya adalah watak, tabiat, akhlak, atau kepribadian seseorang yang terbentuk dari hasil internalisasi berbagai kebajikan (virtues) yang diyakini dan digunakan sebagai landasan untuk cara pandang, berpikir, bersikap, dan bertindak. Sumber Nilai-Nilai (Pusat Kurikulum Balitbang Kemdiknas) : Agama, Pancasila, Budaya, Tujuan Pendidikan Nasional yang diimplementasi-kan dalam 18 nilai karakter, yaitu : religius, jujur, toleransi, disiplin, kerja keras, kreatif, mandiri, demokratis, rasa ingin tahu, semangat kebangsaan, cinta tanah air, menghargai prestasi, bersahabat/komunikatif, cinta damai, gemar membaca, peduli lingkungan, peduli sosial, tanggung jawab.

Pendidikan karakter adalah upaya yang terencana untuk menjadikan peserta didik mengenal, peduli dan menginternalisasi nilai-nilai sehingga peserta didik berperilaku sebagai insan kamil. yang terdiri dari religius, jujur, toleransi, disiplin, kerja keras, kreatif, mandiri, demokratis, rasa ingin tau, semangat kebangsaan, cinta tanah air, menghargai prestasi, bersahabat dan komunikatif, cinta damai, gemar membaca, peduli lingkungan, peduli social, dan tanggung jawab. (Dirjen Dikti dalam Barnawi dan M. Arifin, 2012: 24). Dalam pelaksanaannya, pendidikan karakter bangsa bisa diselipkan dalam setiap mata pelajaran, dalam setiap pembiasaan, dalam kegiatan ekstra kurikuler, maupun dalam kegiatan sehari-hari.

\section{Tinjauan Tentang alat permainan menurut Teori Belajar}

Pembelajaran merupakan salah satu unsur penentu berhasil tidaknya pencapaian tujuan pembelajaran. Pembelajaran ibarat jantung dari proses pendidikan. Pembelajaran yang baik cenderung menghasilkan lulusan yang baik. Demikian pula sebaliknya. Edgar Dale (1946) mengemukakan bahwa pembelajaran dengan verbal saja (ceramah, membaca) mengandung tingkat keabstrakan paling tinggi, sedangkan pengalaman langsung membuat siswa aktif menemukan dan menerapkan suatu konsep memiliki tingkat kekongkritan yang paling tinggi. Yang paling bisa membuat konsep menjadi kongkrit adalah ketika anak terlibat dalam pengalaman langsung dan aktif menemukan sendiri.

Pesan dari bagan Edgar Dale tersebut diperkuat oleh Melvin L. Silberman penulis "101 Cara Belajar Aktif" yang mengatakan: "Yang saya dengar saya lupa, yang saya dengar dan lihat saya ingat, yang saya dengar, lihat, tanyakan, atau diskusikan saya mulai pahami, yang saya dengar, lihat, dan diskusikan, serta lakukan, saya memperoleh pengetahuan dan keterampilan, yang saya ajarkan kepada orang lain, saya kuasai. Senada dengan pendapat edgar Dale, Rubin, Fein, dan Vendenberg (1983) mengemukakan bahwa : permainan dapat memberi pengalaman tentang keadilan, peraturan-peraturan dan kesamaan serta memperkuatkan kebolehan berfikir dalam pelbagai cara. Di 
antara permainan lazim yang dimainkan adalah teka-teki, teka-teki silang kata, nomor kartu, kartu bergambar, catur dan sebagainya. Permainan merupakan saluran untuk melahirkan perasaan dan puncak untuk mendapatkan kegembiraan dan kesenangan. Berdasarkan teori tersebut, maka alat peraga inovasi yang penulis kemukakan adalah peraga, dimana "anak melakukan permainan/bermain" yaitu "bermain cincin akik dan emas dijari jempol tangan".

\section{Tinjauan Tentang Strategi Pembelajaran PAKEM}

Pembelajaran yang saat ini dikembangkan ke seluruh pelosok tanah air adalah Pembelajaran yang Aktif, Kreatif, Efektif, dan Menyenangkan atau disingkat dengan PAKEM. Amanat Permendiknas no. 41/2007: "Proses pembelajaran pada setiap satuan pendidikan harus interaktif, inspiratif, menyenangkan, menantang, dan memotivasi peserta didik untuk berpartisipasi aktif, memberi ruang yang cukup bagi prakarsa, kreativitas, dan kemandirian sesuai dengan bakat, minat, dan perkembangan fisik dan psikologis peserta didik".

Dalam proses pembelajaran, bertanya adalah cara paling mudah dan murah untuk meningkatkan keterampilan berfikir siswa, membuat siswa menjadi aktif, kreatif, dan inovatif. Siswa memiliki keterampilan merumuskan pertanyaan yang mendorong untuk membangun gagasan sendiri, berpikir alternatif, berpikir kreatif, untuk melakukan pengamatan, dan penyelidikan sehingga mereka memberikan jawaban yang berupa gagasan mereka sendiri.

\section{METODE PENELITIAN}

Jenis penelitian yang digunakan dalam penelitian ini adalah jenis penelitian pengembangan dan Penelitian Tindakan Sekolah (PTS). Penelitian pengembangan merupakan metode penelitian untuk menghasilkan produk tertentu, dan menguji keefektifan produk tersebut (Sugiyono, 2010). Penelitian pengembangan digunakan untuk mengembangkan alat permainan cincin akik dan cincin emas. Penelitian Tindakan Sekolah digunakan untuk meningkatkan keprofesionalan guru dalam pembelajaran. Dalam penelitian ini, langkah penelitian pengembangan dimodifikasi menjadi tiga langkah, yaitu identifikasi permasalahan yang menjadi kebutuhan pembelajaran, langkah desain dan pengembangan serta uji coba permainan dan deseminasi. Uji coba produk permainan dilakukan dengan menggunakan penelitian Tindakan Sekolah (PTS). Produk yang akan diuji dalam penelitian ini berupa alat permainan cincin akik dan cincin emas (imitasi) atau kuningan.

Subjek uji coba dalam penelitian ini adalah guru dan siswa kelas 5 SDN binaan Kecamatan Tuntang yang meliputi: SDN Candirejo 01, SDN Candirejo 02, SDN Sraten 01, SDN Karanganyar, SDN Tlogo, SDN Karangtengah, SDN Watuagung 01, SDN Tlompakan 01, dan SDN Ngajaran 03. 
Data dikumpulkan berdasarkan lembar instrument penilaian pengungkapan perilaku, skala sikap dan instrument soal tes. Instrument penilaian pengungkapan perilaku dan skala sikap digunakan untuk mengungkap kefektifan alat permainan cincin akik dan cincin emas imitasi dalam menumbuhkan karakter siswa. Instrumen soal tes dilakukan untuk mengetahui keefektifan penggunaan cincin akik dan cincin emas imitasi dalam proses pembelajaran.

\section{HASIL PENGEMBANGAN DAN PEMBAHASAN}

\section{Identifikasi kebutuhan yang menjadi ide dasar pengembangan alat permainan cincin akik dan cincin emas di jempol tangan}

Berdasarkan langkah-langkah pengembangan yang telah dikemukakan di bagian metode penelitian dan berdasarkan Pedoman lomba inovasi pembelajaran PTK SD Tingkat Nasional (2015 : 3), identifikasi permasalahan kebutuhan media pembelajaran, sehingga menjadi ide dasar pengembangan alat permainan cincin akik dan cincin emas di jempol tangan berikut:

a. Banyaknya kekerasan, tawuran, perkelahian, perampokan, pembegalan, tindakan curang dari para pelajar, dari warga, dan bahkan dari para pejabat negara.

b. Nilai-nilai karakter belum diterapkan dalam kehidupan sehari-hari.

c. Banyak guru yang belum memberikan pendidikan karakter secara maksimal.

d. Mewujudkan tujuan pendidikan nasional dalam menghadapi persaingan global.

2. Desain dan Pengembangan alat permainan cincin akik dan cincin emas di jempol tangan

\section{Alat dan Bahan:}

Alat yang dipergunakan dalam membuat karya inovasi ini adalah :

a. MMT ukuran $80 \mathrm{~cm} \times 50 \mathrm{~cm}$ Untuk dasar dan list untuk layar permainan

b. Triplek ukuran $80 \mathrm{~cm}$ x $50 \mathrm{~cm}$. engsel, kancing, paku rombe.

c. Cincin akik dan cincin emas imitasi /kuningan.

d. Dadu kecil (2 buah)

e. Bulpoin, kertas untuk membuat tanda bintang, kartu soal, kartu jawaban, lem.

f. Bank soal.

g. Tanda emblem / pengenal

h. Petunjuk permainan. 
Pendidikan Karakter Bangsa Berbasis Strategi Pembelajaran PAKEM Melalui Permainan Cincin (Ani Adibatin)

\section{Proses Pembuatan}

a. Membuat rangkaian kata yang menarik dan menantang yang merupakan kependekan dari 18 nlai karakter bangsa.

b. Membuat desain alat peraga inovasi berupa kotak-kotak program "word".

c. Masing-masing kotak diberi huruf/suku kata yang berasal dari kata "bermain cincin akik dan emas di jari jempol tangan".

d. Huruf/suku kata dan layar untuk bermain dibuat bervariasi.

e. Mengeprint desain yang sudah jadi, lalu ditempelkan pada triplek, biar kuat.

f. Triplek yang sudah ditempeli print out, didesain menjadi sebuah kotak seperti kotak papan catur/ tas biar mudah dalam membawanya, awet, serta bisa memuat semua peralatan yang diperlukan.

Hasil pembuatan alat permainan dapat dicermati pada Gambar 1.

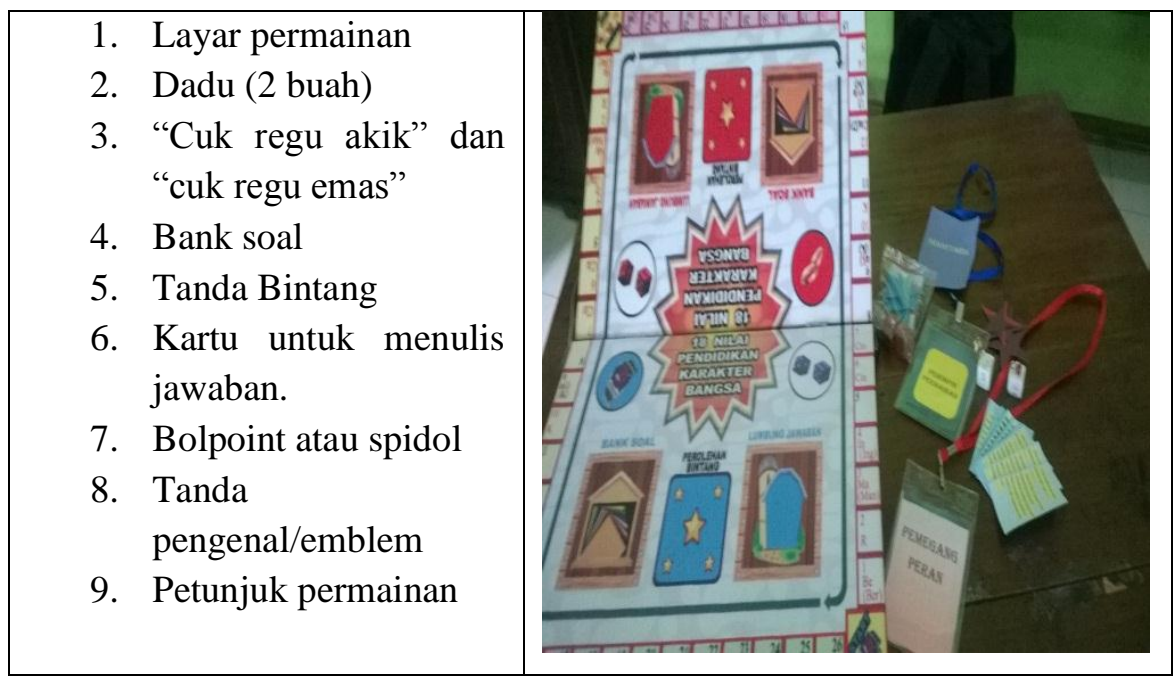

Gambar 1. Hasil pengembangan alat permainan cincin akik dan cincin emas imitasi di jempol tangan

\section{Penggunaan dalam Pembelajaran}

Alat peraga permainan ini bisa dilaksanakan saat pelajaran yang terintegrasi dalam mata pelajaran, saat bermain, saat ekstra kurikuler, maupun dalam kegiatan sehari-hari, dan bisa dilaksanakan oleh semua pendidik, baik guru kelas guru mata pelajaran, maupun guru ekstra kurikuler.

\section{1) Petunjuk Umum:}

a. Alat peraga permainan ini bisa dipakai oleh semua umur, semua tingkatan kelas, semua jenjang pendidikan, hanya tingkat kedalaman materi yang berbeda. 
b. Dalam permainan semua anggota dan wasit harus aktif, kreatif, inovatif, sehingga pembelajaran efektif, dan menyenangkan (PAKEM).

c. Regu yang dalam posisi "main" memberikan pertanyaan, penilaian, perintah, komentar atau koreksi sesuai dengan tingkat kemampuan, tingkat kelas, berdasarkan perintah soal dari perjalanan "cuk" lawan.

d. Regu yang dalam posisi "lawan" bebas memberikan jawaban, mempertahankan jawaban, melakukan permainan peran, ataupun kegiatan sesuai perintah regu main.

e. Alat peraga inovasi ini bertujuan : "membentuk Insan Indonesia yang cerdas, kompetitif, dan berdaya saing tinggi melalui sikap yang sesuai nilai-nilai karakter bangsa menuju pendidikan bermutu dan bangsa yang bermartabat".

f. Huruf besar, kartu huruf, atau suku kata yang terdapat dalam kotak permaianan merupakan kependekan dari nilai-nilai karakter bangsa yaitu Bersahabat, Religius, Mandiri, Ingin tahu, Cinta tanah air, Cinta damai, Kreatif, Kerja keras, Komunikatif, Demokratis, Menghargai prestasi, Semangat kebangsaan, Disiplin, Jujur, Rasa ingin tahu, Peduli lingkungan, Peduli sosial, Tanggung Jawab, Toleransi, Gemar membaca)

g. Huruf merah dalam 18 nilai karakter bangsa diatas merupakan karya inovasi penulis yang akhirnya penulis jadikan sebagai alat peraga pembelajaran yang berjudul 'Pendidikan Karakter Bangsa dengan "Bermain Cincin akik dan Emas Dijari Jempol Tangan" dalam strategi pembelajaran PAKEM di SD' (lihat gambar 2).

2) Petunjuk Khusus :

a. Satu kelompok terdiri dari 3, 5 atau 7 anggota. ( 1 anggota sebagai wasit, sisanya sebagai pemain).

b. Langkah pertama, pemain melakukan hompimpah dilanjutkan pingsut.

c. Pemenang hompimpah dijadikan pemimpin permainan.

d. Pingsut pertama menentukan anggota regu permainan (Regu Akik melawan Emas)

e. Pingsut kedua menentukan siapa yang berhak mulai memberikan pertanyaan. (pemain mengambil soal di bank soal sesuai berhentinya dadu pada angka dalam layar permainan dan membacakannya untuk dijawab oleh regu lawan).

f. Sebelum permainan dimulai, seluruh anggota memilih satu orang sebagai pemegang peran dan satu orang sebagai penulis.

g. Permainan dimulai dari "start" dengan menjalankan "cuk" dadu.

h. Langkah permainan berjalan maju sesuai arah jarum jam. Banyaknya langkah berdasarkan angka yang keluar dalam dadu. 
Pendidikan Karakter Bangsa Berbasis Strategi Pembelajaran PAKEM Melalui Permainan Cincin (Ani Adibatin)

i. Pergantian regu permainan setelah satu kartu soal selasai dibacakan dan dijawab.

j. Lawan yang dapat menjawab setiap soal dengan benar, mendapatkan "bintang".

k. Lamanya permainan berdasarkan kesepakatan (apakah berdasarkan waktu atau berdasarkan banyaknya pergantian permainan secara imbang)

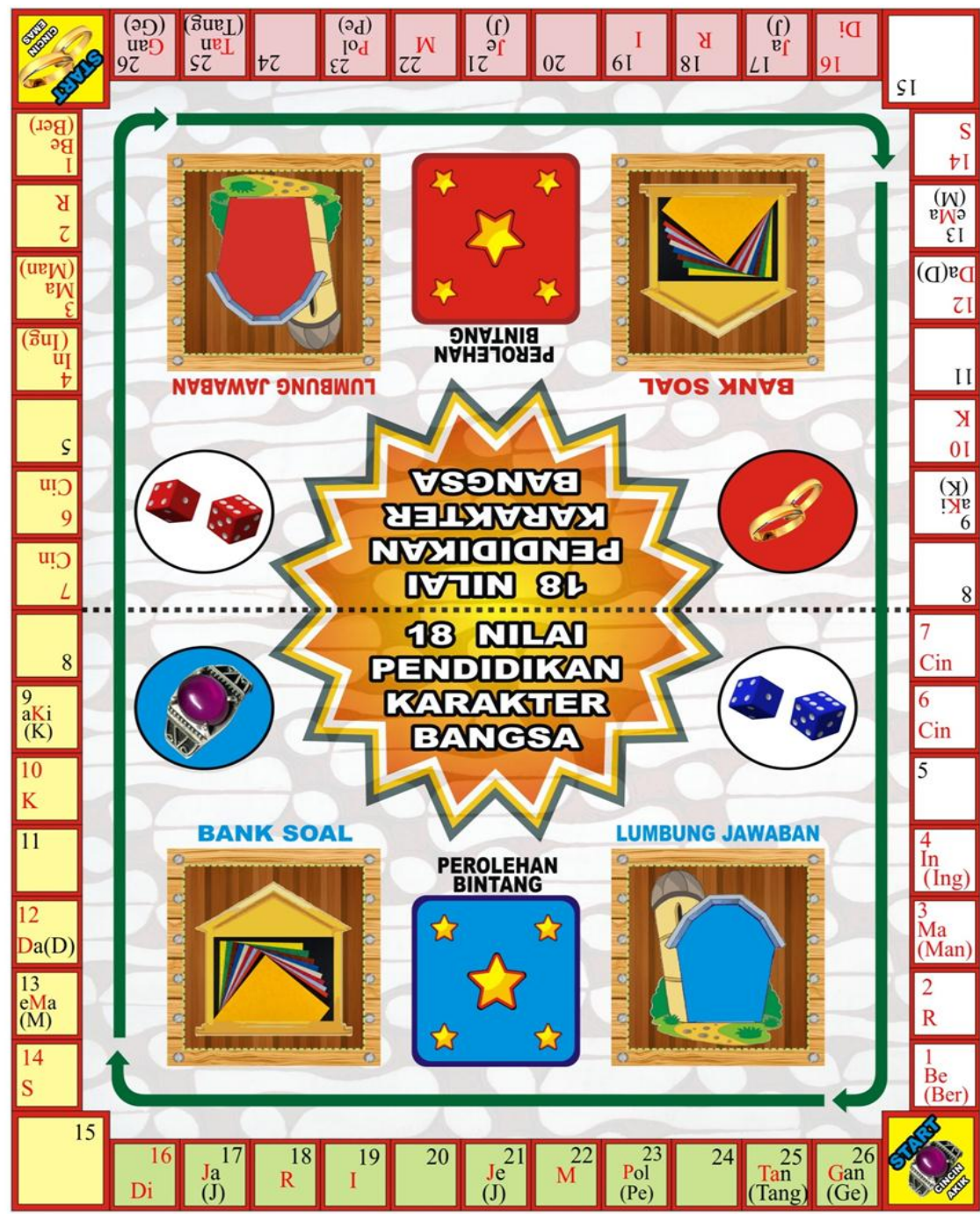

Gambar 2. Layar Alat Prmainan Inovatif Pembelajaran Melalui Permaian Cincin Akik dan Cincin Emas Imitasi di Jempol Tangan 
Tabel 1. Contoh Bank Soal Untuk Kelas V SD

(Pemain Bebas Menambah Jawaban Maupun Menambah Pertanyaan)

\begin{tabular}{|c|c|c|}
\hline $\begin{array}{l}\text { 0. Pada saat kita bermain } \\
\text { dengan teman, kita harus } \\
\text { bersikap bagaimana? } \\
\text { (disiplin, jujur, } \\
\text { bersahabat, tanggung } \\
\text { jawab, dll) } \\
\text {-Bagaimana bila dalam } \\
\text { bermain kita bersikap } \\
\text { curang? (dijauhi teman, } \\
\text { dikucilkan). } \\
\text {-........ }\end{array}$ & $\begin{array}{l}\text { 1. Nilai karakter apakah } \\
\text { yang dimulai dari kata } \\
\text { Ber? (bersahabat). } \\
\text { - Apa arti bersahabat itu? } \\
\text { (Tidak bermusuhan, } \\
\text { bergaul dg baik) } \\
\text { - Apa manfaat kita } \\
\text { bersahabat? (disenangi } \\
\text { teman, tambah teman, dll). }\end{array}$ & $\begin{array}{l}\text { 2. Nilai karakter apa } \\
\text { yang dimulai huruf } \\
\text { R? (Religius) } \\
\text {-Apa arti religius? } \\
\text { bertingkah laku sesuai } \\
\text { ajaran agama, patuh } \\
\text { pada ajaran agama. } \\
\text {-Bagaimana sikap kita } \\
\text { terhadap teman yang } \\
\text { berbeda agama? } \\
\text { (menghormati, } \\
\text { toleransi ) }\end{array}$ \\
\hline $\begin{array}{l}\text { 3. Nilai karakter apa yang } \\
\text { dimulai dari kata Man? } \\
\text { (Mandiri). } \\
\text { - Apa arti kata mandiri? } \\
\text { (tidak tergantung orang } \\
\text { lain) } \\
\text {-Sebutkan manfaat sikap } \\
\text { mandiri (bisa mengatasi } \\
\text { masalahnya sendiri, tdk } \\
\text { tergantung orang lain. } \\
\text {-........ }\end{array}$ & $\begin{array}{l}\text { 4. Nilai karakter apa yang } \\
\text { dimulai dari kata Ing? } \\
\text { (Ingin tahu). } \\
\text {-Apa usaha kalian bila } \\
\text { tidak bisa mengerjakan } \\
\text { PR? (belajar, bertanya, } \\
\text { dll) } \\
\text {-Apa manfaat dari rasa } \\
\text { ingin tahu? ( bisa } \\
\text { mengetahui, tidak } \\
\text { ketinggalan zaman. }\end{array}$ & $\begin{array}{l}\text { 5. - Peragakan saat } \\
\text { kalian bermian } \\
\text { "pasaran"). } \\
\text {-Sikap apa saja yang } \\
\text { diperlukan sebagai } \\
\text { seorang } \\
\text { pedagang?(jujur, } \\
\text { disiplin, menghargai, } \\
\text { dll) } \\
\text {-Apa akibatnya bila } \\
\text { kita tidak saling } \\
\text { menghormati? } \\
\text { (bermusuhan, } \\
\text { pertentangan, } \\
\text { perselisihan }\end{array}$ \\
\hline $\begin{array}{l}\text { 6. Nilai karakter apakah } \\
\text { yang dimulai dari suku } \\
\text { kata Cin? } \\
\text { (Cinta damai, Cinta } \\
\text { Tanah air,) } \\
\text {-Apa yang kamu lakukan } \\
\text { terhadap teman yang } \\
\text { berkelahi? (menasehati, } \\
\text { melerai, dll) } \\
\text { - Buatkan contoh perilaku } \\
\text { sikap cinta damai } \\
\text { (musyawarah, bersikap } \\
\text { adil, menghormati,dll). }\end{array}$ & $\begin{array}{l}\text { 7. Nilai karakter apa yang } \\
\text { dimulai dari suku kata } \\
\text { Cin? } \\
\text { (Cinta Tanah air, Cinta } \\
\text { damai) } \\
\text { - Berikan contoh perilaku } \\
\text { sikap cinta tanah air } \\
\text { (belanja produk dalam } \\
\text { negeri, mencintai budaya } \\
\text { bangsa, ) } \\
\text { - Apa manfaat mencintai } \\
\text { tanah air?(bangsa kuat, } \\
\text { aman, damai) }\end{array}$ & $\begin{array}{l}\text { 8. Nilai karakter } \\
\text { apakah yang dimulai } \\
\text { dari huruf K ? } \\
\text { (Kreatif, Kerja } \\
\text { keras,...) } \\
\text {-Sebutkan contoh } \\
\text { sikap kreatif (suka } \\
\text { mencoba, suka } \\
\text { menemukan yang } \\
\text { baru, dll) } \\
\text {-sebutkan manfaat } \\
\text { dari sikap kreatif } \\
\text { (menghasilkan hal } \\
\text { baru, menambah } \\
\text { pengetahuan, dll) }\end{array}$ \\
\hline
\end{tabular}




\begin{tabular}{|c|c|c|}
\hline $\begin{array}{l}\text { 9. Peragakan saat kalian } \\
\text { bermain "guru-guruan) } \\
\text {-Sikap apa saja yang } \\
\text { diperlukan seorang guru? } \\
\text { (disiplin, sabar, ingin } \\
\text { tahu,) } \\
\text {-Sikap apa saja yang } \\
\text { diperlukan oleh } \\
\text { murid?(sabar, ingin tahu, } \\
\text { disiplin, mandiri) } \\
\text {-...... }\end{array}$ & $\begin{array}{l}\text { 10. Nilai karakter apa } \\
\text { yang dimulai huruf D? } \\
\text { (Demokratis) } \\
\text {-Berikan contoh } \\
\text { pelaksanaan sikap } \\
\text { demokratis dalam kelas } \\
\text { (pembentukan pengurus } \\
\text { kelas, musyawarah karya } \\
\text { wisata, dll) } \\
\text {-Apa manfaat sikap } \\
\text { demokratis? (disenangi } \\
\text { teman, dihargai teman, dll } \\
\text { ) }\end{array}$ & $\begin{array}{l}\text { 11. Apa yang kamu } \\
\text { lakukan bila } \\
\text { menemukan dompet } \\
\text { yang ada alamat } \\
\text { pemiliknya? } \\
\text { (mengembalikan, } \\
\text { menggirim lewat pos, } \\
\text { sms, lapor ke pak rt) } \\
\text {-Sikap apa yang kau } \\
\text { lakukan bila engkau } \\
\text { mengembalikan } \\
\text { dompet tersebut? } \\
\text {-Bagamana } \\
\text { perasaanmu bila } \\
\text { dompet tersebut tidak } \\
\text { kau kembalikan? }\end{array}$ \\
\hline $\begin{array}{l}\text { 12. Nilai karakter apa } \\
\text { yang dimulai dari kata } \\
\text { Man? (Mandiri). } \\
\text { - Apa arti kata mandiri? } \\
\text { (tidak tergantung orang } \\
\text { lain) } \\
\text {-Sebutkan manfaat sikap } \\
\text { mandiri (bisa mengatasi } \\
\text { masalahnya sendiri, tdk } \\
\text { tergantung orang lain. } \\
\text {-........ }\end{array}$ & $\begin{array}{l}\text { 13. Nilai karakter apa } \\
\text { yang dimulai huruf } \mathbf{S} \text { ? } \\
\text { (Semangat kebangsaan) } \\
\text { - Berikan contoh sikap } \\
\text { semangat kebangsaan } \\
\text { (upacara, baris berbaris, } \\
\text { dll) } \\
\text {-Mengapa kita harus } \\
\text { punya semangat } \\
\text { kebangsaan?( untuk } \\
\text { memperkuat ketahanan } \\
\text { bangsa, mempererat } \\
\text { persatuan) }\end{array}$ & $\begin{array}{l}\text { 14. Menyontek } \\
\text { menunjukkan karakter } \\
\text { yang bagaimana? } \\
\text { (tidak jujur, tidak } \\
\text { mandiri, tidak percaya } \\
\text { diri) } \\
\text {-Bagaimana } \\
\text { perasaanmu saat } \\
\text { menyontek? (takut, } \\
\text { was-was, tidak } \\
\text { nyaman, dll) } \\
\text {-Terhadap prestasi } \\
\text { yang kita peroleh, kita } \\
\text { harus bagaimana? } \\
\text { (mensyukuri, } \\
\text { menghargai, } \\
\text { meningkatkan) }\end{array}$ \\
\hline $\begin{array}{l}\text { 15. Perankan saat kalian } \\
\text { mengadakan musyawarah } \\
\text { pemilihan pengurus kelas. } \\
\text {-Sikap apa yang } \\
\text { diperlukan dalam } \\
\text { musyawarah? (disiplin, } \\
\text { saling menghargai, } \\
\text { memberi kesempatan, } \\
\text { menghormati). } \\
\text {-Bagaimana sikapmu } \\
\text { terhadap hasil keputusan? } \\
\text { (bertanggung jawab ikut } \\
\text { melaksanakannya) }\end{array}$ & $\begin{array}{l}\text { 16. Nilai karakter apakah } \\
\text { yang dimulai dari kata } \\
\text { Dis? (Disiplin) } \\
\text {-Jelaskan pengertian } \\
\text { disiplin (sesuai aturan, } \\
\text { mematuhi peraturan, } \\
\text { tepat), dll. } \\
\text {-Berikan contoh sikap } \\
\text { disiplin yang pernah } \\
\text { engkau lakukan (tidak } \\
\text { terlambat, tidak melanggar } \\
\text { aturan, dll). }\end{array}$ & $\begin{array}{l}\text { 17. Nilai karakter apa } \\
\text { yang dimulai dari } \\
\text { huruf } \mathbf{J} \text { ? (Jujur) } \\
\text {-Berikan contoh sikap } \\
\text { jujur (mengakui } \\
\text { kesalahan, } \\
\text { melaporkan apa } \\
\text { adanya). } \\
\text {-Apa manfaat sikap } \\
\text { Jujur ( nyaman, dapat } \\
\text { kepercayaan, } \\
\text { disenangi teman)? } \\
\text {-.... }\end{array}$ \\
\hline
\end{tabular}




\begin{tabular}{|c|c|c|}
\hline $\begin{array}{l}\text { 18. Nilai karakter apa } \\
\text { yang dimulai huruf } \mathbf{R} \text { ? } \\
\text { (Religius) } \\
\text {-Apa arti religius? } \\
\text { bertingkah laku sesuai } \\
\text { ajaran agama, patuh pada } \\
\text { ajaran agama. } \\
\text {-Bagaimana sikap kita } \\
\text { terhadap teman yang } \\
\text { berbeda agama? } \\
\text { (menghormati, toleransi ) } \\
\text {-....... }\end{array}$ & $\begin{array}{l}\text { 19. Peragakan saat kalian } \\
\text { bermain "guru-guruan) } \\
\text {-Sikap apa saja yang } \\
\text { diperlukan seorang guru? } \\
\text { (disiplin, sabar, ingin } \\
\text { tahu,) } \\
\text {-Sikap apa saja yang } \\
\text { diperlukan oleh } \\
\text { murid?(sabar, ingin tahu, } \\
\text { disiplin, mandiri) }\end{array}$ & $\begin{array}{l}\text { 20. Peragakan saat } \\
\text { kalian bertamu, } \\
\text { ternyata tuan rumah } \\
\text { tidak ada, namun } \\
\text { pintunya tidak } \\
\text { dikunci. } \\
\text {-Diruang tamu } \\
\text { tersebut terlihat ada } \\
\text { HP berdering. Apa } \\
\text { yang kamu lakukan? } \\
\text {-Sikap apa saja } \\
\text { terhadap yang kau } \\
\text { lakukan tersebut?... }\end{array}$ \\
\hline $\begin{array}{l}\text { 21. Nilai karakter apakah } \\
\text { yang dimulai dari huruf } \mathbf{J} \\
\text { ? (Jujur) } \\
\text {-Berikan contoh sikap } \\
\text { jujur (mengakui } \\
\text { kesalahan, melaporkan } \\
\text { apa adanya). } \\
\text {-Apa manfaat sikap Jujur } \\
\text { ( nyaman, dapat } \\
\text { kepercayaan, disenangi } \\
\text { teman)? } \\
\text {-.... }\end{array}$ & $\begin{array}{l}\text { 22. Nilai karakter apa } \\
\text { yang dimulai dari huruf } \mathbf{P} \\
\text { ? Peduli Lingkungan, dll } \\
\text {-Berikan contoh sikap } \\
\text { peduli } \\
\text { lingkungan(menjaga } \\
\text { kebersihan, membuang } \\
\text { sampah ditempatnya) } \\
\text {-Apa manfaat sikap peduli } \\
\text { lingkungan? (aman, } \\
\text { bersih, asri) -.... }\end{array}$ & $\begin{array}{l}\text { 23. Nilai karakter } \\
\text { apakah yang dimulai } \\
\text { dari huruf P ? } \\
\text { (Percaya diri, Peduli } \\
\text { Lingkungan, Peduli } \\
\text { Sosial) } \\
\text {-Apa arti percaya dir? } \\
\text { percaya } \\
\text { kemampuannya,tidak } \\
\text { minder) } \\
\text {-Berikan contoh sikap } \\
\text { percaya diri (berani } \\
\text { usul, berani } \\
\text { berpendapat) }\end{array}$ \\
\hline $\begin{array}{l}\text { 24. Nilai karakter apa } \\
\text { yang dimulai dari suku } \\
\text { kata Tang? (Tanggung } \\
\text { Jawab). } \\
\text {-Apa arti tanggung jawab } \\
\text { (berani menanggung } \\
\text { resiko, tidak } \\
\text { mengingkari, mengakui) } \\
\text {-Apa akibat dari sikap } \\
\text { tidak bertanggung jawab? } \\
\text { (pekerjaan tidak selesai, } \\
\text { kacau, berantakan) } \\
\text {-.... }\end{array}$ & $\begin{array}{l}\text { 25. Peragakan, saat kalian } \\
\text { naik angkota ada seorang } \\
\text { nenek yang belum } \\
\text { mendapatkan tempat } \\
\text { duduk. } \\
\text { - Karakter apakah yang } \\
\text { telah engkau lakukan } \\
\text { tersebut? } \\
\text { - Mengapa engkau } \\
\text { melakukan hal itu? }\end{array}$ & $\begin{array}{l}\text { 26. Nilai karakter apa } \\
\text { yang dimulai huruf } \\
\text { G ? ( Gemar } \\
\text { Membaca) } \\
\text {-Mengapa kita harus } \\
\text { gemar membaca? } \\
\text { (tambah ilmu, tambah } \\
\text { wawasan, tidak } \\
\text { ketinggalan zaman) } \\
\text {-Dimana sikap gemar } \\
\text { membaca itu } \\
\text { diperlukan? dimana } \\
\text { saja : disekolah, } \\
\text { rumah, tempat ibadah, } \\
\text { dll }\end{array}$ \\
\hline
\end{tabular}




\section{Hasil Uji Coba dan Pembahasan}

Uji coba pembelajaran PAKEM melalui permainan cincin akik dan cincin emas di jempol tangan di SD binaan (SDN Candirejo 01, SDN Candirejo 02, SDN Sraten 01, SDN Karanganyar, SDN Tlogo, SDN Karangtengah, SDN Watuagung 01, SDN Tlompakan 01, dan SDN Ngajaran 03) dilaksanakan dua kali. Uji coba pertama Awal pekan (Bulan Januari 2015) belum menggunakan permainan inovasi. Uji coba Akhir pekan (Bulan Juni 2015)sudah menggunakan permainan inovasi.

\section{Deskripsi dan Analisis Proses dan Hasil Pembelajaran}

Perbandingan hasil pengolahan data dari pembelajaran yang tidak menggunakan alat peraga inovasi dengan pembelajaran yang menggunakan alat peraga inovasi sbb:

\section{Hasil Analisis Data Deskriptif Kuantitatif variabel karakter siswa}

a. Pertemuan pertama, nilai rata-rata pendidikan karakter siswa kelas 5 SD binaan (sampel 9 SD) sebelum menggunakan karya inovasi 76,55 $\%$.

b. Pertemuan kedua, nilai rata-rata pendidikan karakter siswa kelas 5 dan SD binaan (sampel 9 SD) setelah menggunakan karya inovasi adalah $87,88 \%$

c. Dalam pembelajaran dengan menggunakan permainan inovasi terjadi peningkatan nilai rata-rata pendidikan karakter yang sangat signifikan yaitu dari $76,55 \%$ menjadi $86,88 \%$, berarti ada kenaikan $11,33 \%$

\section{Hasil Analisis Data Deskriptif Kualitatif}

1. Hasil keseluruhan menunjukkan bahwa upaya peningkatan pendidikan karakter untuk mewujudkan pendidikan bermutu melalui strategi pembelajaran dengan "bermain cincin akik dan emas dijari jempol tangan" semakin mantap.

2. Penggunanan strategi peembelajaran dengan karya inovasi ini sangat efektif untuk meningkatkan karakter anak.

3. Berdasarkan kenyataan diatas, diharapkan kepada para pendidik dapat meningkatkan pendidikan karakter bangsa dengan menggunakan berbagai macam cara, salah satu cara yang penulis kemukakan adalah dengan menggunakan alat peraga inovatif melalui "bermain cincin akik dan emas dijari jempol tangan" dalam pembelajaran yang PAKEM". 


\section{Hasil Analisis Data Deskriptif Kuantitatif variabel Hasil Belajar}

Hasil belajar dalam pembelajaran kelas 5 di SD binaan diperoleh data hasil belajar seperti tercantum dalam Tabel 2 .

Tabel 2. Pengolahan Data Hasil Pembelajaran

Kelas 5 SD BinaanKec. Tuntang

\begin{tabular}{|l|l|c|c|}
\hline \multicolumn{1}{|c|}{ No } & Nama SD Binaan & Pertemuan 1 & Pertemuan 2 \\
\hline 1. & SDN Candirejo 01 & 80 & 90 \\
\hline 2. & SDN Candirejo 02 & 77 & 88 \\
\hline 3. & SDN Sraten 01 & 70 & 80 \\
\hline 4. & SDN Karanganyar & 74 & 88 \\
\hline 5. & SDN Tlogo & 77 & 90 \\
\hline 6. & SDN Karangtengah & 78 & 88 \\
\hline 7. & SDN Watuagung 01 & 76 & 87 \\
\hline 8. & SDN Tlompakan 01 & 84 & 91 \\
\hline 9. & SDN Ngajaran 03 & 73 & 89 \\
\hline \multicolumn{2}{|l|}{ Jumlah } & $\mathbf{6 8 9}$ & $\mathbf{6 8 9}$ \\
\hline \multicolumn{2}{|c|}{ Rata-rata nilai } & $\mathbf{7 6 , 5 5}$ & $\mathbf{8 7 , 8 8}$ \\
\hline
\end{tabular}

Rata-rata nilai kelas 5 sebelum menggunakan alat 76,55 \% dan sesudah menggunakan alat permainan $87,88 \%$, berarti mengalami kenaikan nilai $11,33 \%$

Tahap selanjutnya, peneliti melakukan deseminasi (penyebarluasan) alat permainan inovatif ini. Penyebarluasan hasil inovasi pembelajaran kepada teman sejawat dan para pendidik ini kami lakukan lewat pertemuan melalui KKKS, KKG, maupun pembinaan saat implementasi di SD binaan.

\section{SIMPULAN}

1. Hasil karya inovasi pembelajaran "Pendidikan karakter bangsa melalui bermain cincin akik dan emas dijari jempol tangan dalam strategi pembelajaran PAKEM di SD" untuk mewujudkan pendidikan bermutu menunjukan peningkatan pada setiap pembelajaran baik dikelas 5 .

2. Peningkatan hasil pembelajaran dengan menggunakan inovasi permainan mencapai $11,33 \%$ (rata-rata hasil belajar dikelas 5 sebelum penggunakan permainan $76,55 \%$ rata-rata hasil belajar setelah menggunakan inovasi permainan mencapai $86,38 \%$. 
3. Penerapan karya inovasi pembelajaran pada siswa kelas 5 SD bianaan sangat efektif untuk meningkatkan mutu pendidikan guna menghadapi persaingan global.

4. Aktifitas seluruh peserta didik lebih meningkat, kreatif, efektif, efesien, dan menyenangkan, sehingga pengalaman belajar anak lebih awet dan bisa membentuk karakter yang diharapkan.

5. Pelayanan terhadap peserta didik lebih maksimal, sehingga hasil belajar juga lebih maksimal, yaitu terbentuknya Insan Indonesia yang cerdas, kompetitif, dan berdaya saing tinggi melalui sikap yang sesuai nilai-nilai karakter menuju bangsa yang bermartabat.

Berdasarkan simpulan seperti tersebut di atas, disarankan agar:

1. Alat peraga permainan ini bisa dipakai oleh semua umur, semua kelas, semua jenjang pendidikan, dan semua pendidik, hanya kedalaman materi yang berbeda.

2. Alat peraga permainan ini bisa dipakai saat pelajaran dikelas, saat bermain, saat ekstra kurikuler, maupun dalam kegiatan sehari-hari.

3. Kepada semua pendidik baik guru kelas, guru mata pelajaran, maupun guru ekstra kurikuler agar selalu menyelipkan pendidikan karakter bangsa kepada peserta didik.

4. Kepada semua pendidik dan tenaga kependidikan agar selalu mengikuti perkembangan zaman dan selalu berinovasi dalam melaksanakan pembelajaran, sehingga pembelajaran lebih menarik dan hasilnya maksimal.

\section{DAFTAR PUSTAKA}

Arifin, I. 2000. Profesionalisme Guru: Analisis Wacana Reformasi Pendidikan dam Era Globalisasi. Simposium Nasional Pendidikan di Universitas Muhammadiyah Malang, 25-26 Juli 2001.

Arikunto, Suharsini. 2004. Dasar - dasar Supervisi. Jakarta: Rineka Cipta. .2007. Penelitian Tindakan Kelas. Jakarta : PT.Bumi Aksara.a

Atmodiwiro, Soebagio dan Soenarto Tatosiswanto, 1991. Kepemimpinan Pengawas, Semarang: Adhi Waskitho.

Bafadal Ibrahim, 1979. Supervisi Pengajaran Teori dan Aplikasinya dalam Membina Profesional Guru, Jakarta: Rineka Cipta.

Darmiyati Zuchdi. 2009. Pendidikan karakter. Yogyakarta: UNY Press.

Departemen Pendidikan Nasional. 1991. Kamus Besar Bahasa Indonesia. Jakarta: Balai Pustaka.

Depdiknas.2003. Undang-undang No. 20 tahun 2003, Sistem Pendidikan Nasional 
Dirjen Pendidikan Dasar. 2015. Pedoman lomba inovasi pembelajaran PTK SD Tingkat Nasional . Jakarta,

Ratna Megawangi. 2004, Pendidikan karakter. BPMIGAS.

Semiawan, Conny. 1985. Bagaimana Cara Membina Guru Secara Profesional. Jakarta: Journal Pendidikan.

TIM Penyusun. 2013. Bahan Ajar Sertifikasi Guru Pendidikan dan Latihan Profesi Guru (PLPG), Sertifikasi Guru dalam Jabatan. Panitia Sertifikasi Guru Rayon 112 Universitas Negeri semarang. Semarang.

Yusuf A. Hasan. 2002. Pedoman Pengawasan Untuk Madrasah dan Sekolah Umum. Mekar Jaya. Jakarta.

\section{Lampiran 1}

\section{Foto - Foto Kegiatan Saat Diseminasi Dan Saat Implementasi dan}

\section{Penyebarluasan}
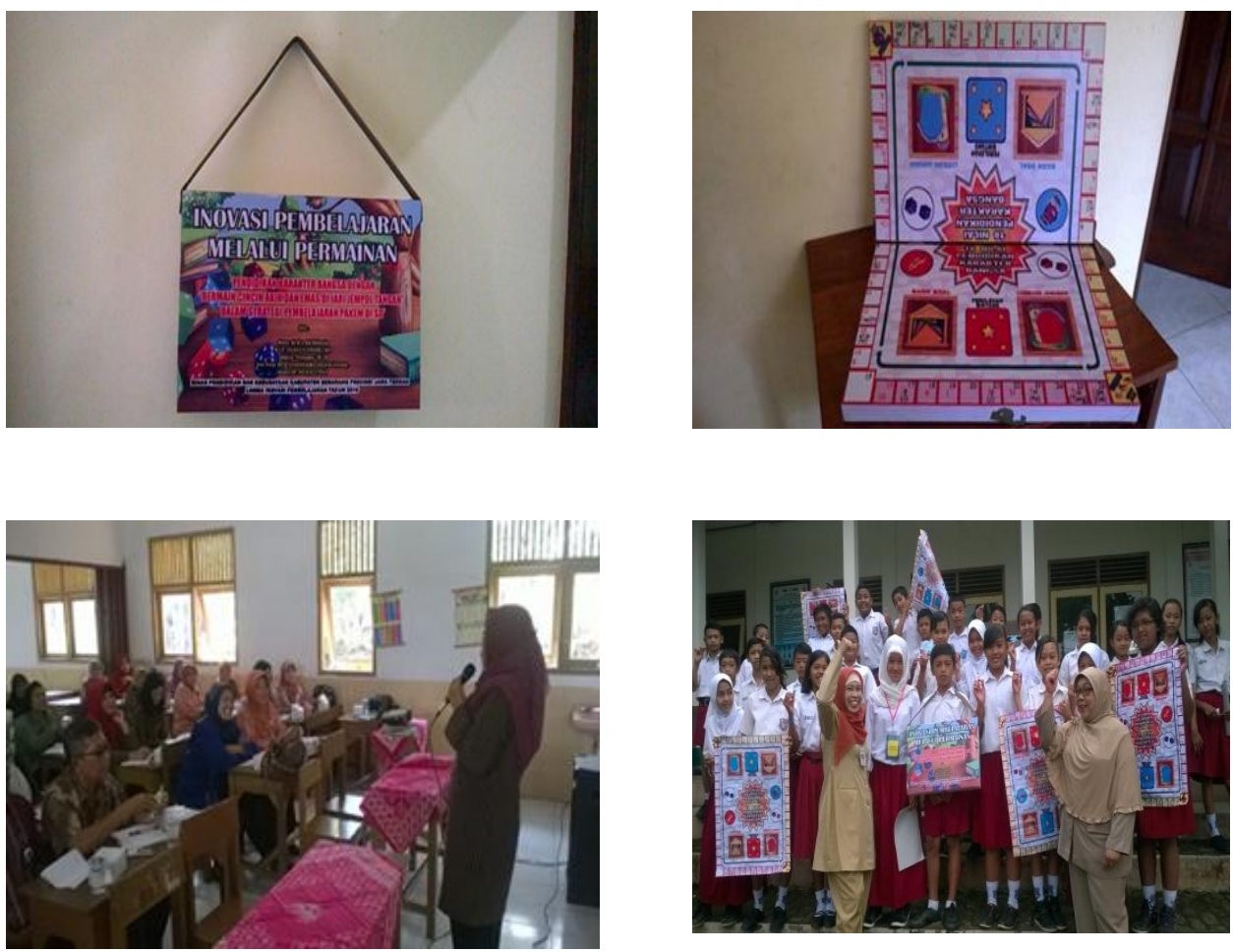

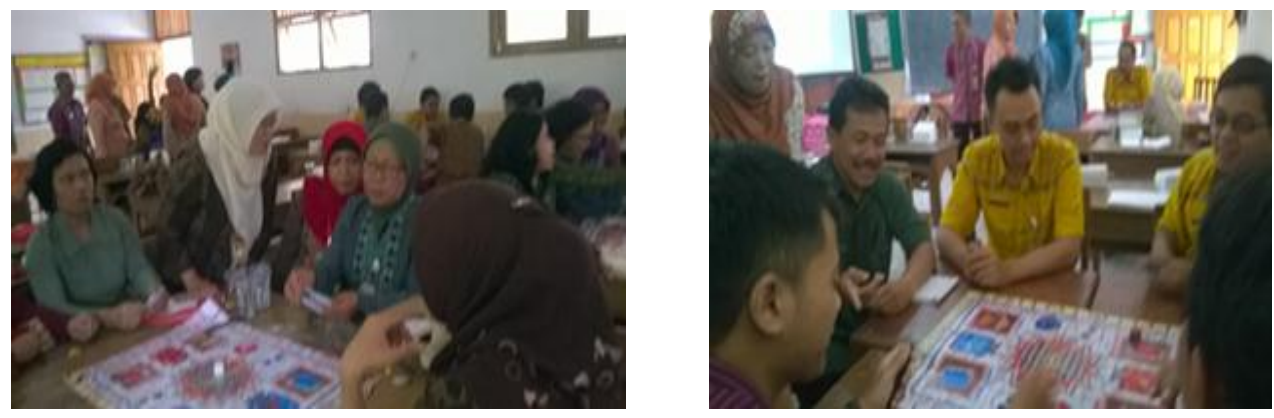

\section{Lampiran 2}

Tabel. 1 Instrumen untuk mengungkap perilaku

Nama anak

Kelas $\quad \ldots . \ldots$... Tanggal

Berilah tanda silang pada alternative jawaban yang sesuai dengan kebiasaan yang engkau lakukan.

\begin{tabular}{|c|c|c|c|c|c|}
\hline NO & PERNYATAAN & \multicolumn{4}{|c|}{ ALTERNATIF PILIHAN } \\
\hline 1. & Saya bergaul dengan .... & semua teman & yang kaya & $\begin{array}{l}\text { yang } \\
\text { pandai }\end{array}$ & $\begin{array}{l}\text { yang } \\
\text { cantik }\end{array}$ \\
\hline 2. & $\begin{array}{l}\text { Segala sesuatu kita } \\
\text { serahkan pada.... }\end{array}$ & Guru & orang tua & Tuhan & usaha kita \\
\hline 3. & $\begin{array}{l}\text { Saat mengerjakan soal } \\
\text { yang sulit, saya... }\end{array}$ & Menyerah & $\begin{array}{l}\text { bertanya } \\
\text { teman }\end{array}$ & $\begin{array}{l}\text { berusaha } \\
\text { sendiri }\end{array}$ & $\begin{array}{l}\text { menyon } \\
\text { tek }\end{array}$ \\
\hline 4. & $\begin{array}{l}\text { Terhadap materi yang } \\
\text { sulit danyang baru, } \\
\text { saya... }\end{array}$ & diam saja & tahu sendiri & Menyerah & $\begin{array}{l}\text { berusaha } \\
\text { ingin tahu }\end{array}$ \\
\hline 5. & $\begin{array}{l}\text { Saya suka bertindak dan } \\
\text { berkata yang.... }\end{array}$ & $\begin{array}{l}\text { menyenang } \\
\text { kan }\end{array}$ & $\begin{array}{l}\text { Menjengkel } \\
\text { Kan }\end{array}$ & menantang & $\begin{array}{l}\text { sesuai } \\
\text { situasi }\end{array}$ \\
\hline 6. & $\begin{array}{l}\text { Saya lebih senang } \\
\text { memakai produk... }\end{array}$ & $\begin{array}{l}\text { daerah } \\
\text { tertentu }\end{array}$ & orang asing & $\begin{array}{l}\text { dalam } \\
\text { negeri }\end{array}$ & luar negeri \\
\hline 7. & $\begin{array}{l}\text { Saya merasa puas bila } \\
\text { saat pelajaran dikelas } \\
\text { bisa .... }\end{array}$ & $\begin{array}{l}\text { mengikuti } \\
\text { apa adanya }\end{array}$ & $\begin{array}{l}\text { menciptakan } \\
\text { cara yg baru }\end{array}$ & $\begin{array}{l}\text { dibantu } \\
\text { teman lain }\end{array}$ & $\begin{array}{l}\text { dipuji } \\
\text { teman }\end{array}$ \\
\hline 8. & $\begin{array}{l}\text { Saya berusaha mengatasi } \\
\text { masalah dengan... }\end{array}$ & $\begin{array}{l}\text { sekuat } \\
\text { tenaga }\end{array}$ & apa adanya & $\begin{array}{l}\text { minta } \\
\text { bantuan }\end{array}$ & Pasrah \\
\hline 9. & $\begin{array}{l}\text { Dalam pengambilan } \\
\text { keputusan, sebaiknya } \\
\text { dilaksanakan dengan.... }\end{array}$ & $\begin{array}{l}\text { lebih cepat } \\
\text { lebih baik }\end{array}$ & $\begin{array}{l}\text { cara masing- } \\
\text { masing }\end{array}$ & $\begin{array}{l}\text { cara saya } \\
\text { sendiri }\end{array}$ & $\begin{array}{l}\text { musyawa } \\
\text { rah }\end{array}$ \\
\hline 10 & $\begin{array}{l}\text { Temaku mendapatkan } \\
\text { hadiah. Saya ... }\end{array}$ & merasa malu & $\begin{array}{l}\text { memberi } \\
\text { selamat }\end{array}$ & $\begin{array}{l}\text { mencari } \\
\text { kekuranga }\end{array}$ & merasa iri \\
\hline
\end{tabular}




\begin{tabular}{|c|c|c|c|c|c|}
\hline & & & & $\mathrm{n}$ & \\
\hline $\begin{array}{l}11 \\
.\end{array}$ & $\begin{array}{l}\text { Saya mau pergi rekreasi, } \\
\text { ada pengumuman kerja } \\
\text { bakti. Saya.... }\end{array}$ & $\begin{array}{l}\text { melanjutkan } \\
\text { pergi }\end{array}$ & $\begin{array}{l}\text { tidak jadi } \\
\text { pergi }\end{array}$ & $\begin{array}{l}\text { ikut kerja } \\
\text { bakti } \\
\text { dulu }\end{array}$ & $\begin{array}{l}\text { pura-pura } \\
\text { tidak tahu }\end{array}$ \\
\hline 12 & $\begin{array}{l}\text { Besok pagi pak guru } \\
\text { rapat. Kami hanya } \\
\text { diberi tugas. Saya akan } \\
\ldots\end{array}$ & $\begin{array}{l}\text { berangkat } \\
\text { terlambat }\end{array}$ & $\begin{array}{l}\text { tetap masuk } \\
\text { sekolah }\end{array}$ & $\begin{array}{l}\text { tidak } \\
\text { masuk } \\
\text { sekolah }\end{array}$ & $\begin{array}{l}\text { menyesuai } \\
\text { kan pak } \\
\text { guru }\end{array}$ \\
\hline $\begin{array}{l}13 \\
.\end{array}$ & $\begin{array}{l}\text { Saya menemukan } \\
\text { dompet disekolah. } \\
\text { Saya.... }\end{array}$ & diam saja & $\begin{array}{l}\text { menyerahkan } \\
\text { pada guru }\end{array}$ & $\begin{array}{l}\text { mengumu } \\
\text { mkannya. }\end{array}$ & $\begin{array}{l}\text { sembunyi } \\
\text { kan }\end{array}$ \\
\hline 14 & $\begin{array}{l}\text { Temanku tidak punya } \\
\text { peralatan sekolah karena } \\
\text { tidak mampu beli. } \\
\text { Saya.... }\end{array}$ & $\begin{array}{l}\text { menjauhi } \\
\text { nya }\end{array}$ & $\begin{array}{l}\text { mendiamkan } \\
\text { saja }\end{array}$ & $\begin{array}{l}\text { tidak usah } \\
\text { memin } \\
\text { jaminya. }\end{array}$ & $\begin{array}{l}\text { memin- } \\
\text { jaminya }\end{array}$ \\
\hline 15 & $\begin{array}{l}\text { Sikap saya terhadap } \\
\text { kebersihan kelas. }\end{array}$ & $\begin{array}{l}\text { menjaga saat } \\
\text { piket }\end{array}$ & $\begin{array}{l}\text { menjaga } \\
\text { setiap saat }\end{array}$ & $\begin{array}{l}\text { sudah ada } \\
\text { petugasnya }\end{array}$ & biasa saja \\
\hline 16 & $\begin{array}{l}\text { Teman yang pernah } \\
\text { menghinaku sakit. } \\
\text { Saya... }\end{array}$ & $\begin{array}{l}\text { pura-pura } \\
\text { tidak tahu }\end{array}$ & $\begin{array}{l}\text { merasa } \\
\text { senang. }\end{array}$ & $\begin{array}{l}\text { Mendiam } \\
\text { kan }\end{array}$ & $\begin{array}{l}\text { menje- } \\
\text { nguknya }\end{array}$ \\
\hline $\begin{array}{l}17 \\
.\end{array}$ & $\begin{array}{l}\text { Secara tidak sengaja } \\
\text { saya memecahkan gelas } \\
\text { ukur. Saya... }\end{array}$ & $\begin{array}{l}\text { membersih } \\
\text { kannya }\end{array}$ & $\begin{array}{l}\text { menyalahkan } \\
\text { teman }\end{array}$ & $\begin{array}{l}\text { mencari } \\
\text { alasan }\end{array}$ & $\begin{array}{l}\text { mencaci } \\
\text { teman }\end{array}$ \\
\hline 18 & $\begin{array}{l}\text { Kegiatan membaca } \\
\text { buku-buku pelajaran } \\
\text { sangat... }\end{array}$ & Kuno & $\begin{array}{l}\text { Membosan } \\
\text { Kan }\end{array}$ & $\begin{array}{l}\text { membuang } \\
\text { energy }\end{array}$ & $\begin{array}{l}\text { menambah } \\
\text { wawasan }\end{array}$ \\
\hline
\end{tabular}

\section{Lampiran 3}

Tabel 2. Instrumen untuk mengungkap Sikap.

\begin{tabular}{|l|l|l|l|l|l|}
\hline \multirow{2}{*}{ NO } & \multicolumn{2}{|c|}{ PERNYATAAN } & \multicolumn{3}{|c|}{ SKALA SIKAP DAN SCORE } \\
\cline { 3 - 6 } & & Selalu & Sering & $\begin{array}{c}\text { Kadang- } \\
\text { kadang } \\
(2)\end{array}$ & $\begin{array}{c}\text { Tidak } \\
\text { pernah } \\
(3)\end{array}$ \\
\hline 1 & Suka membeda-bedakan teman. & & & & \\
\hline 2 & Suka mengganggu teman yang berdoa & & & & \\
\hline 3 & Selalu tergantung pada orang lain. & & & & \\
\hline 4 & Malas tugas yang sulit, malas mencoba & & & & \\
\hline 5 & Suka berkelahi, mencibir, mencaci maki. & & & & \\
\hline 6 & Malu memakai produk dalam negeri. & & & & \\
\hline
\end{tabular}




\begin{tabular}{|l|l|l|l|l|l|}
\hline 7 & Bosan terhadap tugas baru, malas usaha. & & & & \\
\hline 8 & Berputus asa dalam mengerjakan tugas. & & & & \\
\hline 9 & $\begin{array}{l}\text { Memaksakan kehendak, tidak } \\
\text { musyawarah }\end{array}$ & & & & \\
\hline 10 & Merasa iri, merasa hebat sendiri. & & & & \\
\hline 11 & Malas upacara, malas latihan berbaris. & & & & \\
\hline 12 & Datang terlambat, tidak pakai seragam. & & & & \\
\hline 13 & Menyontek, menjiplak, berdusta. & & & & \\
\hline 14 & Menghina, mementingkan diri sendiri. & & & & \\
\hline 15 & Menghindari kerja bakti. & & & & \\
\hline 16 & Tidak mau bezuk, merasa cukup sendiri. & & & & \\
\hline 17 & Suka menyalahkan orang lain. & & & & \\
\hline 18 & Bosan membaca, merasa sudah bisa. & & & & \\
\hline Score tertinggi 54, score terendah 0. & & \\
\hline Nilai skala sikap = perolehan score x 100 : 54 & & \\
\hline
\end{tabular}

Nilai akhir $=$ Nilai perilaku + nilai skala sikap $: 2$

\section{Contoh penghitungan nilai akhir:}

Nama : Budi. $\quad$ kelas : 5. Tanggal : 4 April 2015

Pada penilaian perilaku mendapatkan score $15 . \quad$ Nilai $=15 \times 100: 18=83,33$

Pada penilaian skala sikap mendapatkan srore 50. Nilai $=50 \times 100: 54=92,59$

Nilai akhir yang diperoleh Budi $=83,33+92,59: 2=175,92=87,96$ 